\title{
Comparative Study on Physical Fitness between Indigenous and Non-indigenous Students
}

\author{
Shailandra Chiluwal \\ cshailendra2013@gmail.com \\ Lecturer \\ Central Department of Education \\ Tribhuvan University
}

\begin{abstract}
Physical fitness is essential for all. This is comparative cum cross-sectional study dealing with the physical fitness of students. It was conducted in the secondary schools of Lamjung district with the objective to compare the physical fitness between indigenous and nonindigenous students. Altogether 150 secondary level male students were selected as the respondents consisting 75 for each group. Five schools were selected using purposive sampling method whereas, the respondent students were selected using purposive cum random sampling method. American Association for Health, Physical Education and Recreation (AAHPER) Youth Physical Fitness Test was used to compare the physical fitness of indigenous and non-indigenous students. The test battery included six test items i.e. pullups, sit-ups, standing broad jump, shuttle run, 50-yard dash and 600-yard run-walk. For the comparison of fitness score, mean, SD, CV and Z-test were applied. Fitness status was found better among indigenous students in comparison to non-indigenous students.
\end{abstract}

Key Words: Indigenous and non-indigenous students, physical fitness, speed, flexibility, agility

\section{Introduction}

Physical fitness is a general athletic term which means the capability of the individual to meet the varied physical demand made by a sporting activity as well as regular exercise, without reducing the person to an excessively fatigued state. It can be developed through sporting activity or regular exercise e.g. walking, jogging swimming, cycling, playing sports on regular basis (Davis, Bull, Roscoe, \& Roscoe, 2000). It is used in the context of two meanings: General fitness (a state of health and well-being) and specific fitness (the ability to perform specific sports or occupational skills). In other words, it is the capacity of the heart, blood vessels, lungs, and muscles to function at optimum efficiency. Previously, physical fitness was defined as the capacity to carry out the day's activities without undue fatigue but a now-a-day, it is the body's ability to function efficiently and effectively in work and leisure activities, not only at a set point in time, but at various ages and stages within a person's life cycle (New World Encyclopedia, n.d.).

Agility, balance, body composition, cardio-vascular endurance, co-ordination, flexibility, muscular endurance, muscular strength, power, reaction time, and speed are the components of 
physical fitness (Davis, D., Bull, R., Roscoe, J. \& Roscoe, D., 2000 as cited by Shahi, 2015). Similarly, it is one's ability to execute daily activities with optimal performance, endurance, and strength with the management of disease, fatigue, and stress and reduced sedentary behavior (Campbell, De Jesus, \& Prapavessis, 2013). Thus, a physically fit person is a capacity of the individual to perform a particular task of daily living including sporting activity without tiredness or fatigue. The person who has sound physical fitness can do longer physical work and sporting activity with purposefully and successfully (Singh, Bains, Gill \& Brar, 2012).

Physical fitness is the most important basic need of every individual. It is basic requirement for each and every human being that enables them to participate in sports activities and carry on physical and mental work in efficient manner. Physical fitness is achieved through regular physical activities, sports and exercises. Nixon has defined physical fitness as the organic capacity of the individuals to perform the normal task of daily living without undue tiredness or fatigue having reserves of strength and energy available to meet satisfactorily and emergency demands suddenly placed upon him (Sedhai, 2006).

In early times, people used to be physically fit and healthy as they were involved in different types of physical activities in search of food and escape from the attack of enemies and wild animals. As time passed, different discoveries and inventions made human life easier resulting in lack of in physical activities, and occurring different types of diseases due to inactiveness. Due to illness and other defects on body, people become more and more conscious about their health. Health of person greatly depends upon physical activity and nutrition. Physical activities make us physically fit. It is related to the tasks the person must perform, his potential for physical effort and the relationship of his physical fitness to his total self (Bucher, 2008).

Physical fitness is to the human body what fine tuning is to an engine. It enables us to perform up to our potential. Fitness can be described as a condition that helps us look, feel and do our best. Physical fitness involves the performance of the heart and lungs, and the muscles of the body. And, since what we do with our bodies also affects what we can do with our minds, fitness influences to some degree qualities such as mental alertness and emotional stability (The Centre for Health Promotion and Wellness, n.d.).

More and more physical educators are adding weight control or freedom from obesity, as component of physical fitness. The impetus for this no doubt came from the medical profession. The many medical problems associated with obesity call the cooperative efforts between the medical fields and physical education (Johnson \& Nelson, 1988). Thus, physical fitness is the most important factor in our life. There is the proverb that "Sound mind in a sound body". Therefore, the body is equally important to health of human beings because without body there is no existence of mind.

Due to above stated diversities, people's eating is habit, way of living, involving in different types of physical activities and sports also differs. Racial diversity, culture, language, eating habit, way of living, and physical activities of people of some ecological region is also different which determines the degree of physical fitness. 
Lamjung District is a part of Gandaki Federal State of Nepal. The majority of people are found from Chhetri, Brahmans, Gurung, Tamang, Magar, etc in this district. Different people have different opinions and status on the physical fitness i.e. Brahmin, Chhetri, Gurung, Tamang, Magar, etc. Among them, Gurung, Tamang and Magar are indigenous people whereas Brahmin and Chhetri are known as non-indigenous people. According to the National Foundation for Development of Indigenous Nationalities (NFDIN) Act-2002, indigenous nationalities (Adivasi Janajati) are distinct communities having their own mother tongues, traditional cultures, written and unwritten histories, traditional homeland and geographical areas, plus egalitarian social structures (Indigenous Voice, n.d.). They have played the remarkable role in life style of Nepalese people. Most of the indigenous people of Lamjung district have contributed on the national and international security sectors, i.e. as the British army, Indian army, Singapore police, Hong Kong police and in Nepalese army, and police. Besides, indigenous people have better physical fitness

The people of indigenous caste are the physically stronger than other people, because the young boys at the age of 18 to 25 go to the British and Indian Army. Some of them get admitted in Nepalese police and army. Their economic condition in better is the compassion of other people. Due to their better living standard their physical fitness is automatically better. But the people of non-indigenous community are dependent on agricultural production and most of them are farmers. There is the need of research to compare the indigenous and non-indigenous people in terms of their physical fitness.

There has been no any research works to prove the assumption between the students of these two communities in the past. So there is a clear gap in scientific research works to support the actual status of physical fitness between the male students of secondary level of these two communities. In order to find out the real situation between two groups and meet the research gap, there is a need of undergoing the present research study.

When exercise is regularly done then we will be able to become bodily and mentally healthy and physically fit. If we do regular exercise but we have sufficient knowledge about exercise, it harms negatively in our body, because knowledge of skill is important for every work. Knowingly or unknowingly we are doing different types of physical activities and practice that helps to maintain physical fitness. Components of physical fitness are speed, movement, flexibility, agility, coordination, endurance which is needed for proper development of physical fitness among the secondary level students and youngsters, so there is a need of studying on the physical fitness of indigenous and non-indigenous secondary level students of Lamjung district. This research would provide benchmark data on the physical fitness status. It can help the administrator, supervisor and policy makers for planning and implementing physical education and sports programs at secondary level school. Besides, it would play significant role to other researchers for further study in the field of games, sports, and physical education.

\section{Objectives}

The objective of this research is to compare physical fitness between indigenous and nonindigenous secondary level students of Lamjung District. Therefore, this study explores the 
research questions like 'What is the physical fitness level of students from indigenous group? What is the physical fitness level of students from non-indigenous group? What is the difference in physical fitness among them in terms of pull-ups, sit-ups, standing broad jump, shuttle run and 50 -yard dash and 600-yard run-walk?

\section{Methodology}

Comparative cum cross-sectional study design were applied in this study. The data were compared between indigenous and non-indigenous community's male students of secondary school of Lamjung district. Male were studied in this research because there is the tendency of male recruitment in national as well as international security forces. Total number of indigenous and non-indigenous students of 5 community's secondary level (class 9 and 10) schools of Rainas Municipality were taken as the population of this study where there were altogether 281 students in different school. The sample was taken from secondary schools of Rainas Municipality of Lamjung district. Total the sample size included 75 indigenous and 75 non-indigenous students from sampled five schools. Purposive sampling method was used to select the school and purposive cum random sampling method was applied to select the respondents. There were altogether 150 respondents as the study subjects for this research work. Primary source of data were taken for this study. The researcher was conscious towards research ethics and took permission of the participants mentioning the assurance of the confidentiality of the data.

A standardized and popular AAHPER youth fitness test battery was applied as the tool for data collection. The author is grateful to the developer of this tool. The test battery has six different test items: Pull-ups, sit-ups, shuttle run, standing broad jump, 50-yard dash, and 600-yard runwalk. For the data collection, the researcher visited the respective community and schools and requested to the head teacher in the schools for the permission and managing facilities to conduct the test items for study. While conducting tests, at first the researcher demonstrated the test items among the selected respondents. The assistant scorer recorded the score of the respondents on the notebook systematically. The collected raw data were tabulated, analyzed and interpreted. Some statistical measures and methods such a mean, standard deviation, Coefficient of variance, Z-test etc. were applied and calculated using SPSS Version 16 to analyze the data in order to see the difference in physical fitness between the students of two different groups.

\section{Results and Discussion}

\section{Background Characteristics of the Respondents}

Total 75 male students from indigenous and 75 from non-indigenous group were taken for this study. The age range of the students was 14 to 17 years. They are from grade 9 and 10 of five public schools of Rainas Municipality of Lamjung district.

\section{Comparison on Pull-Ups Test}

Pull-ups are upper body exercise which measures the strength of arms and shoulder muscle. A metal or wooden bar approximately $1 \frac{1}{2}$ inch in diameter is preferred (Johnson \& Nelson, 1988). It is one of the important measures of physical fitness. By treating the pull-ups scores of indigenous and non-indigenous students, the researcher found the result as following: 
Table 1: Comparison of Pull-Ups between Indigenous and Non- indigenous Students

\begin{tabular}{lll}
\hline \multicolumn{1}{c}{ Description } & Scores of indigenous students & $\begin{array}{l}\text { Scores of non-indigenous } \\
\text { students }\end{array}$ \\
\hline Mean & 19.6 & 15.19 \\
Standard Deviation & 4.98 & 6.11 \\
Coefficient of Variation & 13.75 & 40.21 \\
Calculated Z-value & \multicolumn{2}{c}{4.9} \\
Tabulated Z-value at .05 level & \multicolumn{2}{c}{1.96} \\
\hline Conclusion: & It is significant at 0.05 levels of significance. \\
\hline
\end{tabular}

As per Table1, the mean score of indigenous students is 19.6 and the mean score of nonindigenous students is 15.19 in pull-ups i.e. in average each indigenous student did 19.6 times pull-ups whereas each non-indigenous student did it for 15.19 times which shows that indigenous students' arm and shoulder muscle strength is better. The deviation in data was found higher among non-indigenous students in comparison to indigenous students. Z-test was applied by the researcher to see the significant difference between the means of indigenous and non-indigenous students. Therefore, it was found that there is significant difference between the means of indigenous and non-indigenous students.

Thus, indigenous students had better arm and shoulder muscle strength than non- indigenous students. The regular practice of domestic works and agricultural works among indigenous students seems to enhance the arms power which ultimately led to better performance in pull-ups test.

\section{Comparison of Sit-Ups}

Sit-ups examine the efficiency of abdomen and hip flexor muscle of boys. Subject assumes a spine position, legs, extended and feet about 12 inches apart in this physical fitness exercise. Subject's hands with finger interlaced are grasped behind the neck. A supported area to holds the ankles of the subject was used on the follower, and counts its successful, sit-ups (Johnson \& Nelson, 1988). The data collected by the researcher on sit-ups of indigenous and non-indigenous students is presented on the following table:

Table 2: Comparison of Sit-Ups between Indigenous and Non-indigenous Students

\begin{tabular}{lcc}
\hline \multicolumn{1}{c}{ Description } & Score of Indigenous students & Non-indigenous students \\
\hline Mean & 29.39 & 27.63 \\
Standard Deviation & 6.46 & 9.18 \\
Coefficient of Variation & 22.00 & 33.24 \\
Calculated Z-value & & \\
Tabulated Z-value at .05 & & 1.36 \\
level level & & \\
\hline Conclusion: & It is not significant at 0.05 levels of significance. \\
\hline
\end{tabular}


Table 2 shows that mean score of indigenous students is 29.39 and mean score of Non-indigenous students is 27.63 in Sit-Ups Test. The mean score of indigenous students is higher than nonindigenous student. The SD of indigenous students is 6.46 whereas the SD of non-indigenous students is 9.18 due to which the coefficient of variation is higher among non-indigenous Students. The researcher used Z-test to see the significant difference between the means of two groups. There is no significant difference between the means of two groups, although slight difference was seen in mean score between two groups.

By seeing the difference between the mean score the researcher concluded that indigenous students showed somehow better performance in sit-ups than non- indigenous students because indigenous students have better abdominal strength. The difference in performance is seen as indigenous students might be more laborious which enhances their abdominal muscles' strength as compared to non-indigenous students.

\section{Comparison of Standing Broad Jump Test}

Standing broad jump test measures the explosive power of leg muscle. In this exercise, player stands with the feet several inches apart and the toes just behind the take-off line. While jumping, the player swings the arms backward and bends the knees. The jump is accomplished by simultaneously extending the knees and swinging forward the arms (Johnson \& Nelson, 1988). The scores of indigenous and non- indigenous students on standing broad jump are presented on the following table:

Table 3: Comparison of Standing Broad Jump between Indigenous and Non-indigenous Students

\begin{tabular}{lcc}
\hline \multicolumn{1}{c}{ Description } & Indigenous & Non-Indigenous \\
\hline Mean & 2.12 & 2.03 \\
Standard Deviation & 0.19 & 0.20 \\
Coefficient of Variation & 9.18 & 9.95 \\
Calculated Z-value & & 2.90 \\
Tabulated Z-value at .05 level & & 1.96 \\
\hline Conclusion & It is significant at 0.05 levels of significance. \\
\hline
\end{tabular}

Table 3 shows the mean score of Standing Broad Jump of indigenous and non- indigenous students are $2.12 \mathrm{~m}$ and $2.03 \mathrm{~m}$ respectively. The mean scores show that each indigenous student can jump longer distance than non- indigenous students. The deviation in data is slightly higher among non-indigenous students. The difference in mean scores shows the significant difference between the means of two groups. So, the researcher applied the Z-test to find the significant difference between the means.

Thus, indigenous students' leg muscle power was found better than non- indigenous students as indigenous students were found to get involved in daily walking, running and carrying load activities than non- indigenous students. Majority of indigenous students belong to military backgrounds which ultimately inspires them for better physical fitness. 


\section{Comparison of Shuttle Run}

Shuttle run measures the ability of physical speed and agility of the boys. For this, two parallel lines are marked on the floor 30 feet apart. The block of wood is behind one of the lines. The player starts from behind the other line. On the signal "Ready" and "Go" the pupil runs to the blocks, picks one up, runs back to the starting line and places the block behind the line; he then runs again and picks up the second block, which he carries back across the starting line if the scorer has two stopwatches or one with a split second timer, it is preferable to have two pupils running the same time (Johnson \& Nelson, 1988). By administrating test of shuttle run on indigenous and non-indigenous students, the researcher found the result as following:

Table 4. Comparison of Shuttle Run between Indigenous and Non-indigenous Students

\begin{tabular}{lccc}
\hline \multicolumn{1}{c}{ Description } & Indigenous & Non- Indigenous \\
\hline Mean & $10.58 \mathrm{sec}$ & $10.90 \mathrm{sec}$. \\
Standard Deviation & 1.17 & & 0.85 \\
Coefficient of Variation & 11.02 & & 8.29 \\
Calculated Z-value & & 2.88 & \\
Tabulated Z-value at .05 level & & 1.96 & \\
\hline
\end{tabular}

Conclusion:

It is significant at 0.05 levels of significance.

Table 4 shows that the mean score of indigenous students is 10.58 seconds and the mean score of non- indigenous students is 10.90 seconds on shuttle run test which means that indigenous students are more agile than non-indigenous students. But the difference in mean scores only cannot show the difference between the ability of indigenous and non-indigenous students. The deviation in data was higher among indigenous students in shuttle run test. So the researcher applied Z-test to see the significant difference between the means of indigenous and nonindigenous students.

So, the researcher concluded that there is significant difference between the means of two groups i.e. indigenous students' speed and agility is better than non- indigenous students being based on shuttle run test. The regular practice for military enrollments among indigenous students might be the reason for better performance of indigenous students regarding shuttle run test.

\section{Comparison of 50-Yard Dash}

Fifty yard dash measures the ability of speed. It is preferable to administer this test to two or more pupils at a time. Player has to take positions behind the starting line. The starter uses the commands "Are you ready?" And "Go "The player performs downward sweep of the starter's arm to give a visual signal to the timer, who stands at the finish line (Johnson \&Nelson, 1988). By administrating test of 50-yard dash on indigenous and non- indigenous students, the researcher found the result as following: 
Table 5. Comparison of 50-Yard Dash between Indigenous and Non-indigenous Students

Description Score of indigenous students Score of non- indigenous

students

\begin{tabular}{lcc}
\hline Mean & $8.88 \mathrm{sec}$. & $8.61 \mathrm{sec}$. \\
Standard Deviation & 1.19 & 0.85 \\
Coefficient of Variation & 13.40 & 9.82 \\
Calculated Z-value & & \\
Tabulated Z-value at .05 level & & 1.96 \\
\hline Conclusion: & It is significant at 0.05 levels of significance. \\
\hline
\end{tabular}

From the Table 5, it is found that the mean score of indigenous students is 8.88 seconds and the mean score of non- indigenous students is 8.61 seconds on 50-yard dash which shows that non- indigenous students have better performance in comparison to indigenous students. The deviation of data among indigenous students is higher than that of non-indigenous students. But by comparing the means only, the significant difference cannot be determined. So, the researcher applied Z-test to find significant difference between the means of indigenous and non- indigenous students. As per the score in Table 5, significant difference was found between the speed of indigenous and non- indigenous students.

Regarding 50-yard dash non-indigenous students were found to have better performance in comparison to indigenous students. The engagements of non-indigenous students in extracurricular activities such as short distance running, of school was found somehow satisfactory in comparison to indigenous students which might be the reason for the better performance of non-indigenous students in 50-yard dash test.

\section{Comparison of 600-Yard Run-Walk}

Six-hundred yard run-walk measures the efficiency of cardio-respiratory system of young stars. The score is recorded in time. The time to complete the 600 -yard distance either by running or walking is recorded as score (Johnson \& Nelson, 1988). The data collected by the researcher by taking test of 600-yard run-walk on indigenous and non- indigenous students is presented in the table below:

Table 6. Comparison of 600-Yard Run-Walk between Indigenous and Non-indigenous Students

\begin{tabular}{lcc}
\hline \multicolumn{1}{c}{ Description } & Score of indigenous students & Non-indigenous students \\
\hline Mean & 1.97 & 2.08 \\
Standard Deviation & 0.39 & 0.34 \\
Coefficient of Variation & 20.05 & 16.16 \\
Calculated Z-value & & 2.03 \\
Tabulated Z-value at .05 level & & 1.96 \\
\hline
\end{tabular}

Conclusion: It is significant at 0.05 levels of significance. 
As shown in Table 6, the mean score of indigenous students is 1.97 minutes and the mean score of non-indigenous students is 2.08 minutes on 600-yard run-walk test. The mean score of indigenous students is better than non-indigenous students which mean that indigenous students have better endurance than non- indigenous students. The coefficient of variation was 20.05 percent and 16.16 percent of indigenous students and non-indigenous students respectively, which verifies that the deviation of data was higher among indigenous students. Further, the researcher applied Z-test to see the significant difference between the means of indigenous and non- indigenous students.

So, it was concluded that there is significant difference between the means of indigenous and non- indigenous students, i.e., indigenous students have better endurance than non- indigenous students. The reason behind the better performance of indigenous students in 600-yard run-walk is their regular practice for their enlistment in military forces.

\section{Comparison of Composite Scores}

The raw data obtained was analyzed with some descriptive statistic like mean and standard deviation. Further individual T-score was obtained, which was summed to obtain the composite score, which is tabulated and interpreted hereby.

Table 7. Comparison of Composite Score between Indigenous and Non-indigenous Students

\begin{tabular}{lcc}
\hline \multicolumn{1}{c}{ Description } & Score of indigenous students & $\begin{array}{c}\text { Score of non- indigenous } \\
\text { students }\end{array}$ \\
\hline Mean & 331.01 & 303.10 \\
Standard Deviation & 32.82 & 36.51 \\
Coefficient of Variation & 9.91 & 12.04 \\
Calculated Z-value & & 2.17 \\
Tabulated Z-value at .05 level & \multicolumn{2}{c}{1.96} \\
\hline Conclusion: & It is significant at 0.05 levels of significance. \\
\hline
\end{tabular}

Table 7 shows that the comparison of composite score between indigenous and non-indigenous students. The average composite score for indigenous students was found to be 331.01 which is greater than that of non-indigenous students i.e. 303.10. The deviation in result was found higher among non-indigenous students which led the researcher to conclude better physical fitness status among indigenous students.

The performance of indigenous students was found better in pull-ups test, sit-ups test, standing board jump, shuttle un and 600-yard run-walk whereas non-indigenous students performed better in 50-yard dash test, due to which the average composite score of indigenous Students was found better. 
The involvement in daily domestic activities like farming, weight lifting among indigenous students might be the reason for better fitness status in the study area. Furthermore, the attraction towards military enrollment seems to push the fitness status among indigenous students.

\section{Conclusion}

The ready made test battery of AAHPER Youth Physical Fitness test was applied as a tool for this paper which includes pull-ups, sit-ups, standing broad jump, shuttle run, 50-yard dash and 600 -yard run-walk was used to measure the physical fitness of indigenous and non-indigenous students. These test items measure the strength of arms, shoulder muscles, abdominal muscles strength, speed, agility, power of leg muscles and cardio-respiratory endurance. The respondents of this research paper were taken through purposive cum random sampling method. Reflecting on the result and discussion, the researcher found significant difference between the means of indigenous and non-indigenous students. In pull-ups, sit-ups, standing board jump, shuttle run and 600 -yard run-walk score of indigenous students were found better than non-indigenous students. While comparing each test item separately, significant difference was found in all test items except sit-ups test at .05 significance levels in Z-test. This paper concluded that there was found a significant difference between the physical fitness of indigenous and non-indigenous students of Lamjung District. This paper recommended that extramural activities as well as intramural activities should be conducted on the school to increase the performance of physical fitness.

\section{References}

Bucher, C. A. (2008). Foundation of physical education (3rdedition). India: Surjeet Publication.

Campbell, N., De Jesus, S., \& Prapavessis, H. (2013) Physical Fitness. In Gellman M.D., Turner J.R. (Eds) Encyclopedia of Behavioral Medicine. New York NY: Springer,

Davis, D., Bull, R., Roscoe, J., \&Roscoe, D. (2000). Physical education and the study of sports. London: Harcourt Publisher Limited.

Indigenous Voice (n.d.). Who are indigenous people in Nepal? Retrieved from //www. indigenousvoice.com/en/indigenous-peoples/national.html

Johnson, B. L. \& Nelson, J. K. (1988). Practical measurement for evaluation in physical education. India: Surjeet Publication.

Mathews, D. K. (1978). Measurement in physical education. Philadelphia: W.B. Saunders Company.

Sedai, S. P. (2063 BS). Advanced study of physical education. Pokhara: Ozone Books.

Shahi, S.J. (2015). Comparison of general physical fitness between the girl students of Saptagandaki and Nava Kshitiz campus. Unpublished Mini-Research; Tribhuvan University,Nepal.

Singh, A. ,BainsA., Bains, J., Gill, J. S. \& Brar, R. S.(. (2012). Essentials of physical education. New Delhi: Kalyani Publication.

The Centre for Health Promotion and Wellness (n.d.). What is physical fitness? Retrieved from https://medical.mit.edu/sites/default/files/Physical_Fitness_101.pdf

New World Encyclopedia (n.d.). Physical fitness. Retrieved from https://www. newworldencyclopedia.org/entry/physical_fitness. 